\title{
New-Onset Ventricular Tachycardia After Cardiac Resynchronization Therapy
}

\author{
Andrea Di Cori • Maria Grazia Bongiorni • \\ Giuseppe Arena • Ezio Soldati • Gabriele Giannola • \\ Giulio Zucchelli • Alberto Balbarini
}

Published online: 1 March 2007

(C) Springer Science + Business Media, LLC 2007

The publisher regrets that the following article, "New-Onset Ventricular Tachycardia After Cardiac Reysnchronization Therapy" by Andrea Di Cori, Maria Grazia Bongiorni, Guiseppe Arena, Ezio Soldati, Gabriele Giannola, Giulio Zucchelli and Alberto Balbarini, published in Journal of
Interventional Cardiac Electrophysiology Vol. 12, Issue 3, pp. 231-255 was assigned an incorrect DOI number and is therefore missing from this issue's online publication.

The new DOI number for this article is $10.1007 / \mathrm{s} 10840$ 005-6555-1.

The online version of the original article can be found at: doi:10.1007/ s10840-005-6555-1.

A. Di Cori · M. G. Bongiorni · G. Arena • E. Soldati •

G. Giannola $\cdot$ G. Zucchelli $\cdot$ A. Balbarini

Cardiac and Thoracic Department,

University of Pisa, Pisa, Italy

A. Di Cori $(\bowtie)$

Cardiac and Thoracic Department, Cisanello Hospital,

Via Paradisa 2, 56124 Pisa, Italy

e-mail: a.dicori@virgilio.it 